\title{
ISSUES OF WATER RESOURCE MANAGEMENT IN CHINA: IMPLICATIONS ON AGRICULTURE AND FOOD SECURITY IN THE GUANGXI PROVINCE OF SOUTH CHINA
}

\author{
Yumei Huang, ${ }^{1}$ Inibehe George Ukpong2* \\ ${ }^{1}$ School of Civil Engineering and Geosciences, Newcastle University, United Kingdom. \\ ${ }^{2}$ Department of Agricultural Extension and Management, School of Agricultural Technology, \\ Federal Polytechnic, Ekowe, Bayelsa State, Nigeria.
}

E-mail: inibeheukpong@gmail.com

Citation: Huang, Y., and Ukpong, I.G. 2019. Issues of Water Resource Management in China: Implications on Agriculture and Food Security in the Guangxi Province of South China. J. Asian Rur. Stud. 3(1): 70-84

\begin{abstract}
Despite China's great stride in technology development and economic recovery, water remains a major issue of concern. Water has a direct impact on agriculture and food production, hence, water management is critical to achieving food security. This paper reviews in a broader perspective the relationship between water resource management and food security in China, and assesses water resource management interms of water use, pollution and influence of government policies, as well as social and economic systems. It also highlights the challenges of water resource management and its implications on agriculture and food security in the Guangxi province of South China. The review also sets a background upon which further studies and frameworks could be developed to help provide a sustainable solution to regional water management challenges, with a view to achieving improved agricultural production and food security in China and other countries with similar issues. Thus, in the growing quest for economic growth, and owing to the growing need for water in the country, the government of China should ensure through a properly monitored policy framework that water resources are not exploited by a particular sector or region at the expense of other regions in the country.
\end{abstract}

Keywords: Water Management, China, Agriculture, Food Security, Guangxi Province

\section{Introduction}

China is one of the rapid growing economies in the world with enviable advancement in technology and international investment, with various economic implications of high population, including high demand for food and water, food security remains an important index for consideration in the quest for a sustained economic growth in the nation. Water is the key to food security. According to FAO (2012), it takes 2000 to 5000 liters of water to produce one person's daily food. China needs to feed twenty-one percent of world's population by using only six percent of world's freshwater (Wong, 2013). The country's annual per capita renewable freshwater availability is about $2,100 \mathrm{~m}^{3}$, which is far below the G20 average of $9,400 \mathrm{~m}^{3}$ per person per year (Dore et al., 2010). With the rapid growth, China has presented great challenges to manage water resources due to scarcity of water resources, water 
pollution, growing domestic and industrial water demands and requirements for food security (Liu \& Speed, 2004). IFPRI (2009) reported that food prices in China had increased by 12.3 percent in 2007, and there are 130 million people are believed to be food insecure and undernourished. Also, as Chinese population continues to increase, there is a great concern for food security, hence, sustaining food security and the need to improve agriculture have been among the most important goals for governments at all levels in China.

Food security is a critical issue of concern and debates in modern China (Veeck, 2013). China's economy remains one of the fastest growing economies in the world. With a population of about 1.3 billion people, China ranks the most populated nation in the world in 2014. The country faces the growing challenge of food security issues complicated by water management issues, pollution, and large population (Dore, et al., 2010; World Bank, 2012). To sustain the nations economic growth which has been supported by advancement in technology, the socio-economic background of the population must be secured by addressing issues of poverty and food insecurity among the population. These issues must be supported by a vibrantly productive agricultural base, and a growing food production sector supported by properly managed water resources across the nation. In a fast growing economy such as China, characterized by an increase in technology advancement and industrial revolution, pollution remains a major issue of concern. Pollution from the technology and industrial sector coupled with domestic wastes from highly populated households, is bound to have great impacts on environmental resources, including water. In China, various water resources, such as rivers, streams and ponds support the economy in terms of drinking water for humans and farm animals, and food crop production, as well as for other domestic and industrial uses. Water is also particularly vital for agricultural development and food production, hence, water has a direct correlation with national food security. An efficient managed water resource system can promote food security and enhances economic development towards improving people's livelihood.

The problem of water resources in china begins with the need for water in the day to day domestic needs. It also relates to issues of pollution. Water is a vital for the sustainance of life. Water becomes a critical resource of interest in china following the high demand for water due to high population and water-demanding technologies.Apart from domestic use, the large number of industries in China use water as a major ingredient in their production processes. Food industries use enormous quantity of water. Agriculture mainly crop farming and animal husbandary is another major water consuming sector of the Chinese economy.

Apart from air pollution, worsened by China's rapid economic progress, which has triggered increase in contaminated wastes from factories and industries ( $\mathrm{Li} \& \mathrm{Zhang}$, 2014), China has been facing the serious food security as one of the most important issues in economic and social development. China has lost about 8.3 million hectares of arable land, 6.5 per cent of the country's total arable area which pose a challenge to sufficient food production in the country (Song et al, 2013). Also water shortage is threatening agricultural production in some areas such as the north and west of China. It is obvious that water resources in China have been threatened by climate change, domestic and industrial pollution. Global climate change poses great threats to food security and bringing additional uncertainty in water supply in China (Guo et al, 2002). 
Moreover, the rapid economic growth in China has presented great challenges to manage water resources amidstwater scarcity, water pollution, growing domestic and industrial water demands as well as requirements for food security (Liu \& Speed, 2004).This has prompted establishment of the 'Improved Water Resource Management and Drinking Water Safety in Rural China' had been implemented from 2007-2011, which aimed to support Chinese government efforts to improve water resource management and drinking water safety in rural regions of China (UNDP, 2007).

As Chinese population continues to increase, there is a great concern for food security, hence, sustaining food security and the need to improve agriculture has been one of the most important goals for governments at all levels in China. IFPRI (2009) reported that food prices in China had increased by 12.3 percent in 2007 , and there are 130 million people believed to be food insecure and undernourished. On the other hand, water is key to food security. According to FAO (2012), it takes 2000 to 5000 liters of water to produce one person's daily food; therefore, there is a high need to ensure effective water resource management to enhance food security.

Guangxi province in China is an autonomous region with over 48 million population located next to Guangdong province in south of China. It is a largely mountainous region with a favourable climate for agriculture (TCP, 2011). Guangxi province has 937 rivers with over $50 \mathrm{~km}^{2}$ rain collecting capacities, and the primary water sources are the Xijiang River and Dongting Lake (DAGZAR, 2011). These water resources have to be properly managed to support agriculture, particularly crop and animal production. However, water resource management projects have been implemented in Guangxi province, for example, according to the World Bank (2013), the Guangxi Urban Environmental Project aims to improve water quality in support of food security for poverty alleviation in the region. Despite these efforts, Guangxi province still face water problems including water pollution, which make the available water unsuitable for food production and drinking by animals and human, hence, a challenge to food security in the area (UNDP, 2007).

Based on this background, this study aims to evaluate the impacts of water resource management on food security in Guangxi province of south China. The study highlights the problems of water resource management in the area, evaluates the impacts of water resource management on food security, and highlights strategies for solving the water resource problems in Guangxi province.

The research will review water-related issues facing China with specific focus on Guangxi province, south of China. The research will also evaluate the roles of government and communities toward water resource management to promote sustainable agricultural developmentwith a view to achieving food security in the Guangxi province of south China. Based on this background, there is a high need to ensure effective water resource management to enhance food security, which encompasses not only food production, but also access to safe food and adequate nutrition.

This review is to create a background upon which debates and policy can be based to address water resource problems in Guangxi, and achieve food security through water resources management in the region, while highlighting the roles of governments and communities to ensure proper water resource management towards achieving food security in Guangxi province? 
Policy suggestions of this paper is expected to also be relevant to other countries such as Nigeria which shares similar scenario with China, interms of high population growth, extensive land mass and environmental pollution issues.

\section{Method}

This study focused on the review of water resource management in China and its implications on agriculture and food security in the Guangxi Province of South China.

The study used mainly secondary data. In addition to the intensive review of the literature, data on households water use (drinking water) and family sanitation were collected from the National Bureau of Statistics of China. The data were analysed and presented on a frequency chart (graph) showing composition of households based on water use (drinking water) and family sanitation, as well as national total in percentages (See Figure 1). Conceptual framework models were also constructed for the study with reference to existing literatures (see Figures 2, 3 and 4). The model framework gives important background for water management using basic supporting tools and attributes as illustrated by the SWAT (Soil and Water Assessment Tool) model. The input data for SWAT in this research will include: Digital maps (DEM and Stream flow networks, Land use/cover and Soil), Weather data (Daily precipitation and temperature), Hydrologic data (Daily inflow-outflow, parameters related to dams), Soil moisture monitoring data,Crop growth monitoring data and Irrigation monitoring data. By simulating the input data using SWAT, the results/output would include: the hydrologic components (Validation of river discharge, actual evapotranspiration, soil moisture, crop water productivity and stream flow), crop yield, the validation of irrigation volume, and other outputs that related to water quality and sediment.

\section{Results and Discussion}

\subsection{Food Security Issues and water resource management in China}

There are reported cases of water shortage and poor water management in most areas in China (Jiang, 2009). Water shortage in China has been attributed to rapid socioeconomics growth and environmental degradation, as well as identified human impact with respect to other influence on water distribution (Chen et al., 2001). Chu et al. (2004) noted that waste water reuse and reclamation as an efficient way to cope with water scarcity and severity of water pollution. Economic growth and development, including activities of domestic and international trade within china have not only resulted in water over use, but also contribute to water pollution and pose a problem to water resource management. Some regions in china are relatively poor with regards to water resources, and as a result of water pollution (Guan \& Hubacek, 2007).

The growing diversion of water resources for urban and industrial consumption portrays a serious threat to China's food security. This is so as agriculture, particular food production remains threatened by insufficient water supply (availability) and water pollution. This views also formed the basis for argument in a report if China can feed itself (Heilig et al., 2000). 
China's economy faces a growing threat from the challenge of management of water resources, which are continually exposed to growing municipal and industrial pollution. Flooding jeapardized food security safety as well as human health across the country (Wu et al., 1999). Water management in China, should therefore entails making available a safe and sufficient water for domestic and agriculture use, by regulating industrial exploitative use of water., and ensuring efficient management of water resources against pollution, flood and safety risks.

Liu \& Xia (2004) affirmed that most areas in northern China are vulnerable to water resource crisis. Natural change and human activities affect water resource renewable ability. Water problem has become very severe in most vulnerable areas in China. Water shortage is a problem in China. Rapid increase in population has triggered the exploitation of land and water resources in the quest for agricultural development, and contributes to the alarming phase of water problems across China. This views corroborates the report by (Ma et al., 2005).

Water is indeed a scarce commodity and competition for water resources in China is intense. Every part of China is potentially at risk of water overuse or pollution. This includes the arid zone of north-west part of china currently facing water issues (Qi \& Guodongi, 1998; Ma et al., 2005). Pollution increases the stress on water complicated by population growth, urbanization and industrialization. Yet there is a slow concurrent investment in water resource management (Ma et al., 2009).

There is apparently politics surrounding issues of water resource distribution and management, this is complicated by lack of public consciousness for the need for environmental protection, lack of legal structures to promote environmental protection, remains an important challenge to sustainable water resources management framework and poor awareness of pollution worsened by poorly managed domestic and industrial waste (Ma et al., 2009).

There is a growing agricultural demand, rapid urbanization, industrialization, environmental degradation and climate change-related threat to water resources in China (Varis \& Vakkilainen, 2001). There is also an unprecedented competition for water between agriculture, forestry and animal husbandry and domestic use. Water either wasted or exploited (Qi \& Guodong, 1998). There exist an inequality in the distribution of water across China, with selected areas facing serious water deficiencies, for instance, Northern China faces serious water problem, including the arid northwestern China (Varis \& Vakkilainen, 2001; Qi \& Guodongi, 1998; Liu \& Xia, 2004).

There is an uneven distribution of water resources in China as north and west have greater water resources than the south and east. This fact makes this study even more imperative to discuss the issue of water management in the Guangxi region of south China towards promoting efficient water resources use and conservation (Qi \& Guodong, 1998). With the growing issues of pollution and climate change in the world, especially in Asia and Africa, this study is aimed to provide additional reference background for debates and practical research. In particular, the study is also expected to remain an important literary compendium and reference resource for further studies on water resource management and food security issues in China and other countries.

This review is expected to also be very useful to policy makers in developing nations facing population and water problems. In particular, Nigeria is one of the suitable case studies in Africa, with its continuously increasing trend in population 
growth which makes the country the most populated black nation in the world, the country has pollution problems generated from the petroleum industry and the country's advancement in technolology, as well as industrial and agricultural revolution in recent years.

In recent years, food security has become one of the most important issues in economic and social development debates in China. Ronnie (2012) has reported that China has lost about 8.3 million hectares of arable land, 6.5 per cent of the country's total arable area. Also water shortage is threatening agricultural production in some areas such as the north and west of China. The average annual per capita available is only $10 \%$ of the world average. Those will cause the decrease of the quantities of the food productions and cause the problems of the food supplying issues. Supply-siderelated problems are not the only challenges facing Chinese agriculture, the quality of the existing food products has also a big issues. The tainted milk event, which reported that eating this milk will cause the death of babies and children, gave a warning to the Chinese government to strengthen the power of controlling the food quality issue. Wheeler \& Kay (2011) highlighted that agriculture is central to food security and economic growth in developing countries, but food production requires substantial amounts of quality water. Because nearly $70 \%$ of the water used throughout the world are accounted for agricultural use of water and the majority of this water is used for irrigation (Disrude, 2004). In addition, the low quality water, such as high salt concentrations water, will limit the amount of water a plant can take up and resulting in high plant stress and decreased crop yields. On the contrary, improper agricultural methods may elevate concentrations of nutrients and sediment loads to the agricultural water, which will disqualify them from the agricultural usage. Therefore, water quality is vital for the success of agriculture, and in turn, proper agriculture management practices are necessary for maintaining the substantial amount of quality water.

The main issues about water resources in China are water pollution and water shortage, therefore, in order to solve the problems of water resources in China, the three methods should be considered which including exploiting new water resources, saving water and treating wastewater, and political perspectives on water resources management. One of the reasons for water shortage in China is the uneven distribution both in space and time. Therefore, remote water transfer can solve this problem fundamentally, for example, transfer water from one region which is well-endowed with rich water resources, to another region which has poor water resources or lots of citizens who cannot access fresh water. The famous case study for the remote water transfer in China is the diversion of water from the south to the north project. In 30 October, 1952 , Mao Zedong said that:"In our country, the water in south is much and in north is little, if it is possible, the cities in north can borrow some water from the cities in south." (Trier, 2006). This statement is considered as the origin of the divert water from the south to the north, and it appeared by the Great Leap-era Political Bureau directive of 1958 and on December 1979, the project planning office was established by the Ministry of Water Resources (Zhang, 2004).

According to James (2008), the diversion of water from the south to the north project refer to three sets of diversions, which are the Eastern, Middle and Western routes, each serving separate areas, however, the coastal city of Tianjin will receive water from both the Eastern and Middle routes. The Eastern and Middle routes will pass 
under the Yellow river, while the West routes will directly replenish the Yellow river. The advantage of this project is that it can solve the problem of water shortage fundamentally. This project would divert 44.8 billion cubic meters of water every year (about half the amount of water consumer in California annually) from Yangtze River in south of China to the Yellow river basin in north China (International Rivers, 2012).

Secondly, the aim of exploring new water resources such as expansion of water gathering grounds, reservoir storage and construction of desalination plant is increasing water availability for drinking, agriculture, industries and livestock. Since 1960s there are lots of institutes and universities studying and researching seawater desalination. In China, the famous example for exploring new water resources is seawater desalination. However, in China, the application of desalination to date is still limited. For example, by 2004 , the total capacity of seawater desalination is about $18,000 \mathrm{~m}^{3} / \mathrm{d}$, however, the biggest plant in Dalian City, with a capacity of $10,000 \mathrm{~m}^{3} / \mathrm{d}$ (Zhou \& Tol, 2003). Therefore, by now, in China, the main method to solve the water shortage in exploring new water resources is the diverting water from the south to the north project.In China, the main water pollution includes: industrial pollution, agricultural pollution and domestic pollution.

Pollution treatment not only can protect the environment, but also protect water resources. According to SDWF (2008), wastewater is water that has been used and must be treated before it is released into another body of water, so that it does not cause further pollution of water sources. Waste water treatment is the process of taking waste water and making it suitable for discharge back into the environment. Waste water in cities refers to household sewage and parts of industrial waste water. For example, in 1998, the total discharge waste water in cities of China is 35.79 billion cubic meters; however, the household sewage amounted to 16.29 billion cubic meters, accounting for 45.5 percent of total waste water discharge (Yang et al., 2000). The waste water treatment is becoming the main method in managing water pollution in China, and it has achieved a big target on waste water treatment. For example, according to Tengxian Environmental Protection Bureau Office (2011) reported, the TengxianZhongyi Ceramic Company used 260,000 tons industrial water per year, however, there is about 24,000 tons of waste water has been treated and reused.

\subsection{Political Perspectives on Water Resource Management}

Water use relates to climate change, as well as economic and agricultural use. Agriculture consumes water, and in the quest for increased agricultural production in the country, there is a need for more efficient ways of water transfer across the country (Zhou \& Tol, 2005).

Water management is critical to economic development of a country. With the high advancement in technology, China has the potentials to improve on its wate resource management. Government policies should be made to favour such technologies, so as to enhance agricultural development, food security and industrial development. An efficient and equitable distribution of water across China, irrespective of the province, would benefit the economy, rural households and social structures in the country. A well developed water resource management would promote domestic sanitation, food safety and improvement in human health issues. A typical example of the criticality of water resource issues in China can be explained by the constraints posed by poor water 
management to people's livelihood, and households sanitation and drinking water (See, Figure 1 below).

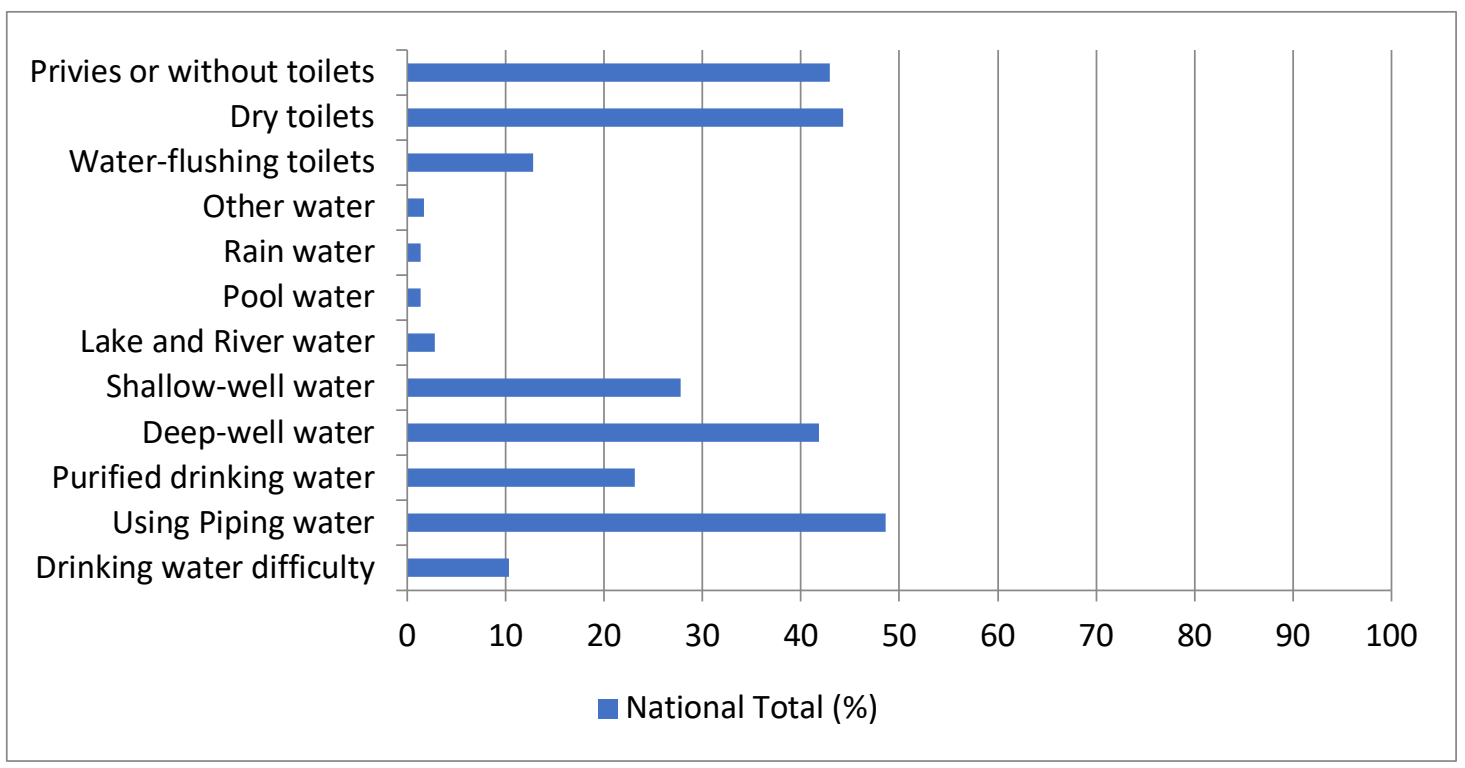

Figure 1. Composition of households based on water use (drinking water) and family sanitation Source: Authors' computation from National Bureau of Statistics of China Data, 2008.

Water management issues can may not be unconnected with the obvious reduction in the basic domestic sanitation by households, as only $12.8 \%$ of the people nationally use water flushing toilets, with as much as $87.2 \%$ using either dry toilets $(44.3 \%)$ or privies or without toilets $(42.9 \%)$. It is a fact that water flushing toilets supports human sanitation and prevents environmental pollution, as there is a possibility that a proportion of those without toilets could engage in wrongful or wanton disposal of human faeces in natural water sources and land, which pose a threat to the safety of food chain and food safety across the country. Water resource management is therefore a national issue, and responsibility of the governments, (including central government, region government and environmental department). For example, according to Asmal (1994), in South Africa, the roles of central governments for managing water supply can include: managing the nation's water resources in public interest and ensuring all of citizens can have access to adequate water and sanitation services. However, the provincial governments are focusing on the responsibility for assuring service provision.

In China, the system for water resources management includes multiple institutions and is very complicated compared with the example of South Africa. Not only can the central government and region government manage the water, but also hydraulic departments, geological departments, urban construction departments, municipal departments and environmental protection departments can attend to manage water resources. Some of them are managing alone; however, some of them will work together. For example, ground water and surface water are managed separately by hydraulic departments and geographical departments; urban water supply is the responsibility of urban construction departments and the environmental protection departments and municipal department control wastewater discharge and treatment. 
Therefore, Water resource management in China is more complicated than South Africa, according to Yang et al., (2000), water resources management in China might this be characterized as 'multiple dragons governing waters.

Comparing with other countries, China has a complicated structure of water-related policy frame. For example, in China, the Ministry of Water Resources is managing the overall administration of water resources, and the Ministry of Water Resources is the leading ministry overseeing most resource management matters and there are a set of central government ministries are involved in water policy in China. According to the World Bank (2006), the legal basis for the institutional arrangement in China can be set out in three laws, which are The Environmental Protection Law (EPL), Water Pollution and Control Law (WPCL) and the Water Law (WL).

The EPL is the principal law for environmental protection in China. The purpose of this law is protecting and improving people's environment and the ecological environment, preventing and controlling pollution and other public hazards, safeguarding human health and facilitating the development of socialist modernization (Environmental Protection Law of the People's Republic of China, 1989). As The World Bank (2006) outlined "it defines the rights and duties of all levels of government, industries, organizations, and individuals with respect to environmental protection". For water resources management, it focuses on water quality standards and discharge of waste water. The WPCL is adopted in 1984 and revised 1996. The purpose of The Water Pollution and Control Law is preventing water pollution in major water bodies in China (Lee, 2006). According to The World Bank (2006), the purpose of this law and is for water monitoring and the protection of water resources for drinking water.The WL acts as the key law defining the nature of water resources management in China. It has played important roles in promoting the rational development, utilization, saving and protection of water resources; Preventing and controlling water disasters and conducting the sustainable use of water resources (Lee, 2006).

\subsection{The model framework}

This article is part of a broader ongoing study on water resource management and food security in China. The study was framed under the premise that social and economic systems, and water management have both direct and indirect relationships with food security. In addressing these linkages, we hope to model the over-ridding influence of government policies (and political issues) over the social and economic system and water management, as well as food security. Food security was dissected to capture issues of food safety, food production, food availability and consumption, as well as food import. In particular, the study is intended to assess theinfluence of water management on food security towards inferring policy implications. The model framework that gives important background for water management has been summariezed into large scale and local factors, as shown in Figures $2 \& 3$, using two basic supporting tools such as SWAT (Soil and Water Assessment Tool). The large scale system level factors linksthe relationship between different systems, such as, social and economic system, water resource management system and food security system (Figure 2). Each system has several components as would be incorporated into the proposed model. 


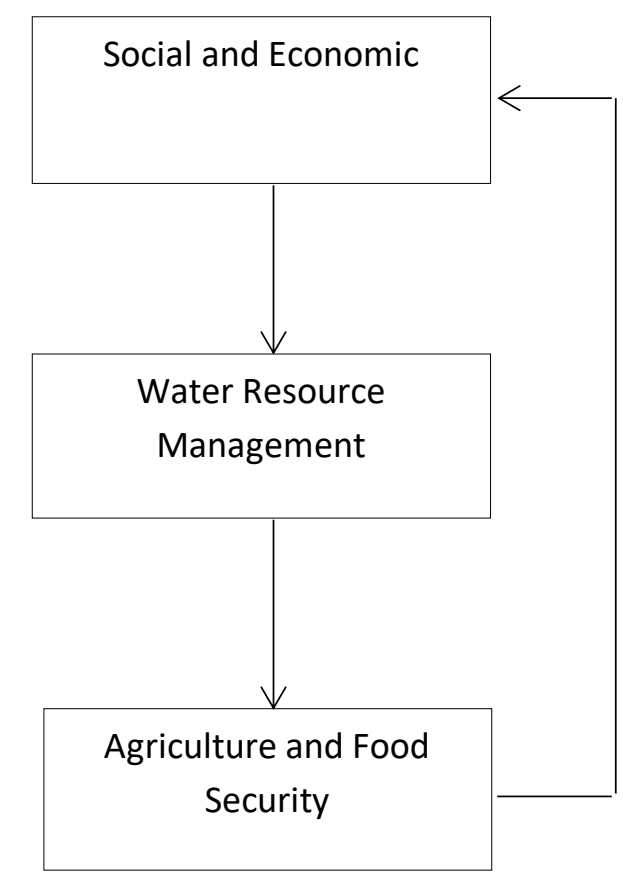

Figure 2. Summarized Large Scale Factors Relationship

\subsection{Modelling Water-Crop Relationship}

Figure 3 shows the summarized local factors relationship, involving water and crop, linking the factors within the local systems, such as water security and crop yields. Water security promotes improved crop yield which enhances food security and ensures provision of income to farmers, which all-together promote improved livelihood. In other words, a proper water management would result in food security and human livelihood improvement. These facts further highlight the importance of this review.

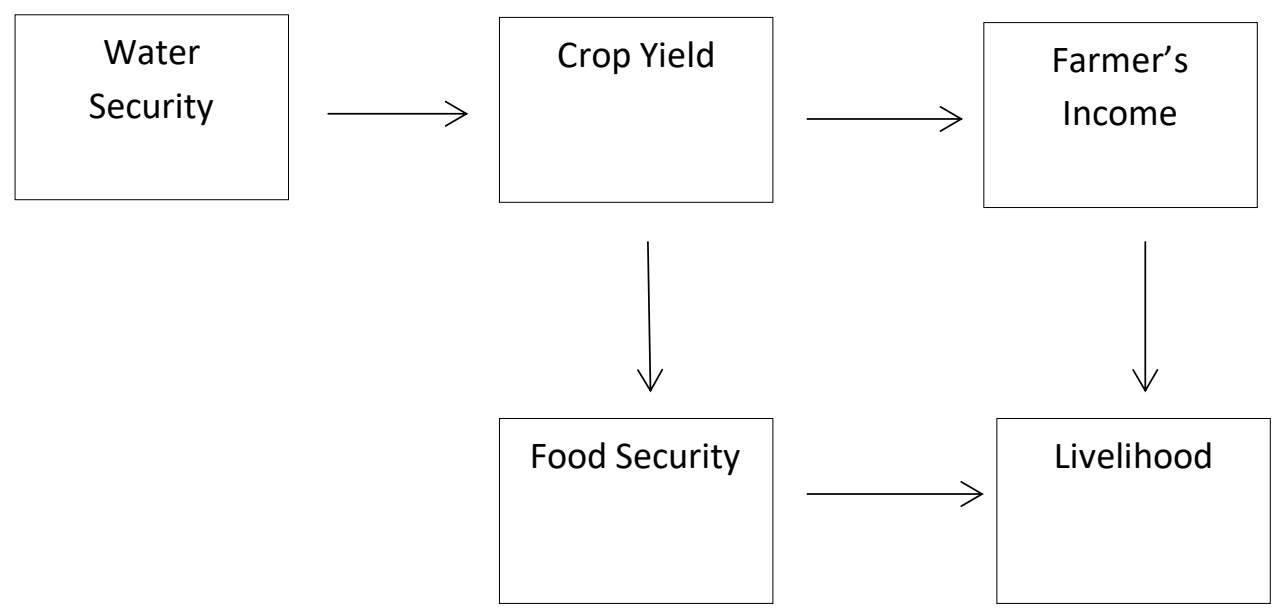

Figure 3. Summarized Links between Local Factors 


\subsection{The SWAT model}

The Soil and Water Assessment Tool (SWAT) is a river basin or watershed scale model to simulate the quality and quantity of surface and ground water, predict the environmental impacts of land use, water resource management and climate change (Arnold et al., 1998). The SWAT model was chosen for this research as it represents hydrological processes and crop growth dynamics. It can be up-scaled to small catchment size and reflect a number of irrigation and land management options. SWAT is being used to guide understanding and not as a "true" representation of water and food production. During the research, the SWAT model will be used to achieve five specific objectives, including; assessment of water resources availability; estimation of crop water requirement and crop yield; Assessment of crop water productivity of different crops cultivated in different soil, climatic and water resource conditions; and scenario analysis to predict the impacts of water resource management on food security (crop yield).

The Data Input-Output for SWAT model is illustrated in Figure 4 below.

Input

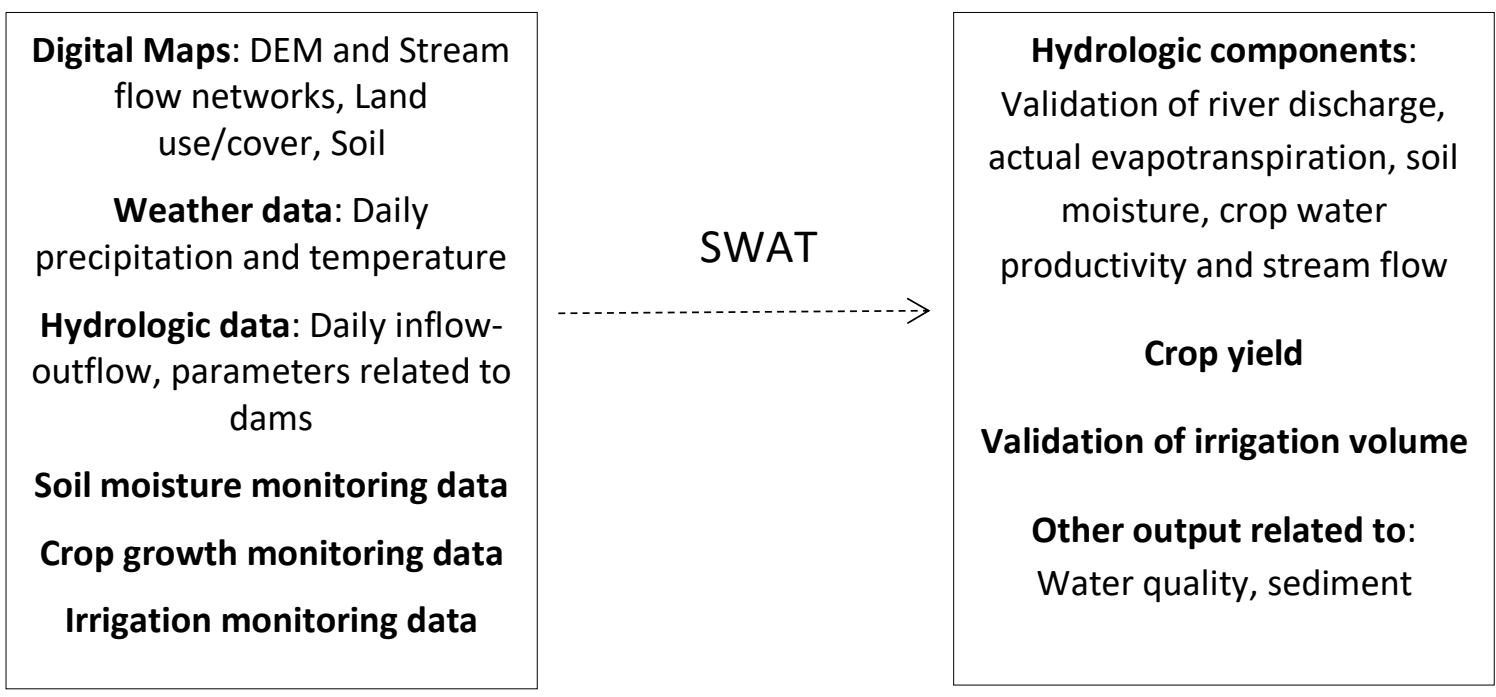

Figure 4. Data Input-Output for SWAT model

\section{Conclusion and recommendations}

China is one of the fastest growing economies in the world. Despite the nation's great stride in technology development and economic recovery, water remains a major issue of concern. Issues of water management are major contents of debates in China, ranging from pollution to distribution and scarcity of water in the face of a competitive water demand for domestic, industrial and agricultural uses. It is obvious that pollution, industiralization and politics guiding policies of water distribution is a hindrance to sustainable water management in China. It is imperative to note that water resource problem in any part of China is a potential threat to agriculture and food production in 
the entire nation. This is obvious as water issues in one province would trigger livelihood and food security issues, which could result in increased pressure on provinces that are not affected through increased economic dependency and migration from affected areas. Apart from regional air pollution, which remains China's major environmental challenge, the country has insufficient water resources, which affects domestic access to sufficient and safe drinking water and impacts negatively on agriculture and food production. This fact corroborates with the report by (Shao et al., 2006). Water is a critical topic of debate in modern China, characterized by a growing economic development, supported by advancement in technology and international trade. Water management becomes a critical issue as China is facing severe water scarcity under high demand from its large population (Jiang, 2009). Judged by the findings and assumptions of this study, we also suggest the following:

1. That to address the issue of water pollution and other water management indices, the government of China should ensure through a properly monitored policy framework that water resources are not exploited in the growing quest for economic growth.

2. Industries should be made to manage their water contaminating wastes to prevent conscious and accidental disposal into water resources, which could cause pollution. Government should ensure a strict policy to monitor abuse of water resources and holds accountable individuals or corporate entities that violate regulations on water protection, and water safety.

3. Increased investment in research and technology to promote discoveries and policy recommendations towards ensuring efficiency in water management across the nation.

4. There is a need for public awareness to contribute to environmental protection through proper waste management, efficient water usage and avoidance of water pollution.

5. To effectively manage water resources, there is a need to close the gap in water distribution between the different region in China by developing technology or investment in water distribution technology to ensure adequate water distribution.

6. Improvement in water quality and water supply mechanisms would promote agricultural development, food safety, and food security in areas where food production is hindered by inadequate water supply and water pollution.

7. The government should make effective policies to help close the gap of water distribution inequality among the Chinese population.

8. In furtherance of this study towards achieving efficient water resource management for sustainable food security in China, an in-depth research is proposed using the SWAT and GIS models.

\section{Conflict of Interest}

Authors do not have any conflict of interest.

\section{Acknowledgement}

Authors acknowledge the supervisory assistance from Prof. Qiuhua Liang and Dr. Paul Quinn of Newcastle University, United Kingdom. 


\section{References}

Arnold, J. G., Srinivasan, R., Muttiah, R. S. \& Williams, J. R. (1998). Large-area hydrologic modeling and assessment: Part I. Model development. J. American Water Resour. Assoc. 34(1): 73-89.

Chu, J., Chen, J., Wang, C. \& Fu, P. (2004).Wastewater reuse potential analysis: implications for China's water resources management, Water Research, 38: 27462756.

Chen, X., Zong, Y., Zhang, E., Xu, J. \& Li, S. (2001). Human impacts on the Changjiang (Yangtze) River basin, China, with special reference to the impacts on the dry season water discharges into the sea, Geomorphology, 41: 111-123.

DAGZAR (2011).Superiority of natural resource- Guangxi Water.General Situation of Guangxi Agriculture.Department of Agriculture of Guangxi Zhuang Autonomous Region.

Dore, D., Peiyuan, G., Nette, A \&An, J (2010): Ed: Carmody, L. Water in China: Issues for responsible Investors. Responsible Research Inc. Available: www.sustainalytics.com. Accessed: April 20, 2015.

FAO (2012).Water and Food Security.World Water Day-2012.Food and Agriculture Organization of the United Nation (FA). March 2012.

Fawell, J., \&Nieuwenhuijsen, M. J. (2003).Contaminants in drinking water Environmental pollution and health. British Medical Bulletin, 68(1), 199-208.

Global Health and Education Foundation (GHEF) (2007).Pollution in China.Available:[https://www.koshland-sciencemuseum.org/water/html/en/Treatment/Agricultural-and-Industrial-Pollution-inChina.html]. Accessed: 22 October 2015.

Guan, D. \&Hubacek, K. (2007). Assessment of regional trade and virtual water flows in China. Ecological Economics, 61 (159-170).

Heilg, G. K., Fischer, G. \&vanVelthuizen, H. (2000). Can China feed itself? An Analysis of China's food prospects with special reference to water resources. International Journal of Sustainable Development and World Ecology, 7(3), 153172.

IFPRI (2009). Food Security Portal: China. Available from:

http://www.foodsecurityportal.org/china/resources [Accessed on 22 January 2013].

Jiang, Y. (2009). China's water scarcity, Journal of Environmental Management, 90: 3185-3196.

Jun, X., \&Yongyong, Z. (2008). Water security in north China and countermeasure to climate change and human activity. Physics and Chemistry of the Earth, Parts $A / B / C, 33(5), 359-363$.

Lee, S. (2006). Water and Development in China: The Political Economy of Shanghai Water Policy (Singapore: World Scientific Publishing Company).

Li, M., Zhang, L., 2014. Haze in China: Current and future challenges, Environmental Pollution, 189, 85-86. 
Liu, B \& Speed, R. (2004).Water Resources Management in the People's Republic of China.International Journal of Water Resources Development. Volume 25, Pp 193-208.

Liu, C. \& Xia, J. (2004). Water problems and hydrological research in the yellow river and the Huai and Hai River basins of China, Hydrological processes, 18: 21972210. Doi: 10.1002/hyp.5524.

Ma, J.Z., Wang, X. S. \& Edmund, W. M. (2005). The Characteristics of ground-water resources and their changes under the impacts of human activity in the arid Northwest China-a case study of the Shiyang River Basin, Journal of Arid Environments, 61, 277-295.

Ma, J., Ding, Z., Wei, G., Zhao, H. \& Huang, T. (2009).Sources of water pollution and evolution of water quality in the Wuwei basin of Shiyang river, Northwest China, Journal of Environmental Management, 90, 1168-1177.

Peng, S. (2011).Water resources strategy and agricultural development in China. Journal of experimental botany, 62(6), 1709-1713.

Pimentel, D., Berger, B., Filiberto, D., Newton, M., Wolfe, B., Karabinakis, E., ...\&Nandagopal, S. (2004). Water resources: agricultural and environmental issues. BioScience, 54(10), 909-918.

Qi, F. \&Guodongi, C. (1998). Current situation, problems and rational utilization of water resources in arid north-western China, Journal of Arid Environments, 40: 373-382.

Qin, B., Zhu, G., Gao, G., Zhang, Y., Li, W., Paerl, H. W., \& Carmichael, W. W. (2010). A drinking water crisis in Lake Taihu, China: linkage to climatic variability and lake management. Environmental management, 45(1), 105-112.

Shao, M., Tang, X., Zhang, Y. \& Li, W. (2006). City clusters in China: air and surface water pollution, Frontiers in Ecology and the Environment, 4(7): 353-361.

TCP (2011).Guangxi Zhuang Autonomous Region.The China Perspective. Available from:

http://www.thechinaperspective.com/topics/province/guangxi-zhuang-autonomousregion/ [Accessed on 22 January 2013].

UNDP(2007). Improved Water Resources Management and Drinking Water Safety in Rural China. United Nations Development Program: China. Available from:

http://www.undp.org.cn/projects/56957.pdf [Accessed on 22 January 2013].

Varis, O. \&Vakkilainen, P. (2001). China's 8 Challenges to water resources management in the first quarter of the 21st Century, Geomorphology, 41, 93-104.

Veeck, G. (2013). China's food security: past success and future challenges, Eurasian Geography \& Economics, 54 (1)42-56

World Bank (2013).Guangxi Urban Environment Project.Projects \& Operations.The World Bank-Working for World Free of Poverty.

World Bank (2012).China: Improving Water Resource Management \& Pollution Control in the Hai Basin. Available: 
http://www.worldbank.org/en/news/feature/2012/09/03/china-improving-waterresource-management-pollution-control-in-hai-basin. Accessed: April 19, 2015.

Wu, C., Maurer, C., Wang, Y., Xue, S. \& Davis, D. L. (1999).Water Pollution and Human Health in China.Environmental Health Perspectives, 107 (4), 251-256.

Yang, J., Ge, C. \& Gao, S. (2000). Corporatisation of Urban Water supply and Wastewater treatment facilities in China. Paper presented at the Workshop on Environmental Financing held in Beijing on 21-23 November 2000: Chinese Research Academy of Environmental Sciences, Beijing 100012, China.

Zhou, Y \&Tol, R. S. T. (2005). Water use in China's Domestic, Industrial and Agricultural Sectors: An Empirical Analysis. Working Paper, NU-67.Une, 12. 